\title{
Kinetic extraction of basic dye using vegetable oil as a solvent
}

\author{
Norasikin Othman a, b, ${ }^{*}$, Norul Fatiha Mohamed Noah ${ }^{a}$, Ooi Zing Yi a, Muhammad Bukhari Rosly ${ }^{\text {a }}$ \\ Hilmi Abdul Rahman ${ }^{a}$, Roslina Rashid ${ }^{c}$ \\ a Department of Chemical Engineering, Faculty of Chemical and Energy Engineering, Universiti Teknologi Malaysia, Skudai 81310, Johor, Malaysia \\ ${ }^{b}$ Centre of Lipids Engineering \& Applied Research (CLEAR), Ibnu Sina Institute for Scientific and Industrial Research (Ibnu Sina ISIR), Universiti \\ Teknologi Malaysia, 81310 UTM Johor Bahru, Johor, Malaysia \\ ${ }^{c}$ Bioprocess and Polymer Engineering Department, Faculty of Chemical and Energy Engineering, Universiti Teknologi Malaysia, 81310 Skudai \\ * Corresponding author: norasikin@cheme.utm.my
}

Article history

Received 19 November 2017

Accepted 10 December 2017

Graphical abstract<smiles>CN(C)c1ccc2nc3cc/c(=[N+](/C)Cl)cc-3sc2c1</smiles>

\begin{abstract}
Vegetable oil such as palm oil and corn oil are more environmentally friendly and economic compared to petroleum based solvent. In this study, liquid-liquid extraction (LLE) of basic dye methylene blue (MB) from simulated textile wastewater using di(2-ethylhexyl) phosphoric acid (D2EHPA) in vegetable oil was investigated. The parameter of extraction studied included types of solvent, D2EHPA concentration, types and concentrations of stripping agent and initial $\mathrm{pH}$ of aqueous waste solution. D2EHPA concentration was varied in the range of $0.005-0.50 \mathrm{M}$. The results showed that palm oil provided good potential as a solvent in the MB extraction. Almost $100 \%$ of MB was extracted at 0.1M D2EHPA in palm oil with distribution ratio of 38 which is reasonably high. The extracted MB in loaded organic phase are capable to re-extracted back for dye recovery using $0.6 \mathrm{M}$ of sodium bicarbonate $\left(\mathrm{NaHCO}_{3}\right)$ as a stripping solution.
\end{abstract}

Keywords: Palm oil, methylene blue, textile wastewater, removal, liquid-liquid extraction

\section{INTRODUCTION}

Dye is the most obvious indicator of water pollution. It was used widely in various industries such as, cosmetic, rubber, paper, textile in order to become colouring agents to the products [1]. Normally, basic dyes are commonly applied to polyester fibers, wool, silk, and acrylic fibers due to increasing development in production of synthetic fiber lately [2]. Every year, an enormous volume of coloring agents were made. Also, there are more than 10,000 dyes that are commercially available with variety chemical and physical properties [3]. The existence of lower concentration of dyes in wastewater which is less than $1 \mathrm{ppm}$ for some dyes is highly detectable and harmful [4]. The dyes upset the biological activity in water bodies. They also pose a problem because they may be mutagenic and carcinogenic and can cause severe damage to human beings, such as the dysfunction of kidney, reproductive system, liver, brain and central nervous system [5-6].

Therefore, before discharged into the environment, industrial effluents containing dyes must be treated. The treatment methods include membrane filtration, photodegradation, adsorption, coagulation-flocculation, ion exchange, advanced oxidation, flotation, chemical reduction, ozonation, electrochemical, solvent extraction and biological treatment but meet some limitations [7-10]. Currently, the most widely used combination of techniques for dye removal from dye-containing industrial effluents is by physio-chemical means. Adsorption of dye stuffs on cotton fabric wastewater using semiactivated carbon has been proposed by Ozoh [11]. The problem regarding to this method is disposal approach of the spent activated carbon after removing of dye stuffs. Besides, removal and recovery of acid dyes from wastewater using ion exchange were investigated by many researchers [12]. Ahmad et al. reported that membrane separation process offered the method for increasing the removal of dyes [13]. However, fouling membrane is the main problem for this technique. Solvent extraction or liquid-liquid extraction (LLE) has been successfully studied for both anionic and cationic dyes from wastewater $[14,15]$. They found that almost $100 \%$ of dyes were extracted. The principle of this methods is solute can distribute itself in a certain ratio between two immiscible diluents/solvents. It will affect the equilibrium of the system that was rely on the selected of both diluent and carrier. The advantage of liquid-liquid extraction includes high purification, ease of automatic operation and scale up and high through put. The importance parameter affecting liquidliquid extraction process is carrier concentration, stripping agent concentration and $\mathrm{pH}$ of feed solution.

In this research study, the efficiency of LLE of MB using D2EHPA in palm oil as organic phase/solvent was studied. The palm oil is produced from harvested fruits bunches of oil palm trees which is abundant in Malaysia. It is harmless to health and environment compared to petroleum based solvent in terms of toxicity and biodegradability. Thus, the objective of this study is to determine the feasibility of using vegetables oil as a solvent in extraction of MB from simulated wastewater. Investigation on the dye extraction and stripping performance were study. Also, operating conditions were optimized.

\section{EXPERIMENTAL}

\section{Chemicals and reagents}

The following reagents were used: methylene blue (minimum assay of $82 \%$ ) from QRec, di(2-ethylhexyl) phosphoric acid (D2EHPA) 
(assay of 95\%) from MERCK, SPAN 80 (assay of 99\%) from Sigma, kerosene (assay of 78\%) from Sigma, palm oil and corn oils from Lam Soon Edible Oils Sdn. Bhd. Malaysia. For stripping agent; sodium hydroxide $(\mathrm{NaOH})(98 \%$ assay) and $\mathrm{NaCl}(99 \%$ assay) were obtained from J.T. Baker. $\mathrm{NaHCO}_{3}(99.5 \%$ assay) was obtained from GCE laborotary chemical and $\mathrm{Na}_{2} \mathrm{CO}_{3}$ obtained from EmSure ${ }^{\circledR}(99 \%$ assay). All the chemicals were of analytical grade and used without further purification.

\section{Experimental procedures \\ Preparation of MB solution}

Methylene blue (MB) IUPAC name is 3,7- bis(dimethylamino)phenothiazin-5-ium chloride. It is a cationic dye. It is classified as $\mathrm{CI}$ Basic blue 9, CI solvent blue 8, CI 52015. It has a molecular formula $\mathrm{C}_{16} \mathrm{H}_{18} \mathrm{~N}_{3} \mathrm{ClS}$ and molecular weight of $319.85 \mathrm{~g} / \mathrm{mol}$. The MB used was of analytical grade so it was used without further purification. A stock solution of $1000 \mathrm{mg} / \mathrm{L}$ was prepared by dissolving an appropriate quantity of $\mathrm{MB}$ in a liter of deionized water. The working solutions were prepared by diluting the stock solution with deionized water to give the appropriate concentration of the working solutions.

\section{Extraction and stripping process}

Equilibrium solvent extraction were divided onto two reaction which is forward and backward extraction. Equal volumes $(10 \mathrm{ml})$ of organic solution which contain $0.1 \mathrm{M}$ of D2EHPA in palm oil and $25 \mathrm{ppm}$ of simulated methylene blue solution were mixed using mechanical shaker at 320rpm for 18 hours. After forward extraction completed, the mixture was carefully poured into the separating funnel for phase separation $(15 \mathrm{~min})$. The bottom part of treated aqueous solution was carefully separated from the organic solution. The concentration of methylene blue in the aqueous solution was measured by UV spectrophotometer. The wavelength of maximum absorption $(\lambda \max )$ for methylene blue was $650 \mathrm{~nm}$. Meanwhile, the extracted methylene blue in organic solution was calculated based on mass balance. The procedures were repeated for other parameters including different concentration of carrier and $\mathrm{pH}$ of aqueous solution. The optimum condition was obtained.

Backward extraction so called stripping extraction was carried out by mixing equal volume of methylene blue loaded organic solution and stripping agent $\left(\mathrm{NaHCO}_{3}\right)$ using same setting as forward extraction. After $15 \mathrm{~min}$ of phase separation, the bottom part of stripping aqueous phase was carefully segregated. UV spectrophotometer was used to measure the concentration of stripping methylene blue. The procedures were repeated with different stripping agent concentration. All the experiments were run in duplicate and analytical parameters were performed in triplicate for each run.

\section{Determination and calculation}

The distribution ratio (D), percentage of extraction (E), and stripping $(\mathrm{S})$, were calculated as per the following equations:

$D=\frac{[a y e]]_{\text {org }}}{[d y e]_{a g}}$

$E(\%)=100 x \frac{\left[\text { aye] loge }-[\text { aye }]_{\text {aq }}\right.}{[\text { dye }}$

$S(\%)=100 x \frac{[d y e]_{\text {frr }}}{[\text { dyel }}$

Where [dye $]_{\mathrm{aq} 0}$ is the initial dye concentration of aqueous phase $(\mathrm{mg} / \mathrm{L}),[\text { dye }]_{\mathrm{aq}}$ is the dye concentration of aqueous phase after extraction $(\mathrm{mg} / \mathrm{L})$, [dye $]_{\text {org }}$ is the dye concentration in the organic phase $(\mathrm{mg} / \mathrm{L})$ and $[\mathrm{dye}]_{\text {int }}$ is the dye concentration of internal phase after backward extraction $(\mathrm{mg} / \mathrm{L})$.

\section{RESULTS AND DISCUSSION}

\section{Effect of vegetable oil types}

Liquid membrane can be modified to "green liquid membrane" by using environmentally friendly diluent. The effect of vegetables oil such as palm oil and corn oil as a solvent in the extraction of MB was investigated. The results as shown in Figure 1 indicate that both vegetables oil had potential to use as a LLE of MB using D2EHPA as a carrier. Almost $100 \%$ of MB was extracted from the solution. Mean that the oils can act as a perfect solvent/diluent in the process. Because -of palm oil is cheaper and easy to get compared to corn oil, it was used as a solvent for further the studies. In addition, palm oil has been found to work well for extraction of phenol using supported liquid membranes (SLM) [16].

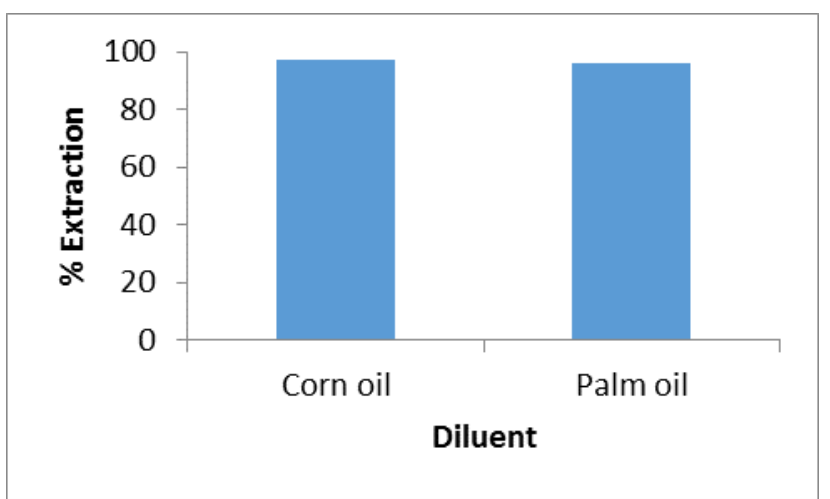

Figure 1 Extraction performance on difference types of vegetable oils (Experiment conditions: [dye] $=25 \mathrm{ppm}$, agitation speed $=320 \mathrm{rpm}$, duration $=18 \mathrm{hrs}, \mathrm{pH} 6 \pm 0.1$, feed:organic ratio $=1: 1)$

\section{Effect of carrier concentration}

The effect of D2EHPA concentration on the extraction of cationic dye range from $0.005-0.5 \mathrm{M}$ was shown in Figure 2. The experimental data plotted illustrate the extraction percentage increase dramatically with increase in carrier concentration from 0.005 to $0.01 \mathrm{M}$. Then, it increase gradually and reached maximum $96 \%$ at $0.1 \mathrm{M}$ of carrier. Further increase the concentration of carrier the extraction percentage became plateau. The trend confirms that even though using palm oil as diluent, D2EHPA is effective in extracting cationic dyes. During extraction, carriers were reacted with dye and form complex. More carriers provided enhance the extraction efficiency. The saturation capacity of the organic phase for the complex reached at optimum $0.1 \mathrm{M}$ D2EHPA. The equilibrium of reaction was achieved when all carriers get associated with dye ion and form complex [17]. D2EHPA is anionic carrier with negative charges showed attractive force to cationic dyes and its good performance on cationic dyes was evaluated using kerosene as diluent [13]. The extraction efficiency of using kerosene was comparable to this study which was using palm oil as diluent. Palm oil has a density of $887.5 \mathrm{~kg} / \mathrm{m}^{3}$ and a viscosity of $130 \mathrm{mPa} \cdot \mathrm{s}$ at $20{ }^{\circ} \mathrm{C}$. Meanwhile, kerosene has a density of $790 \mathrm{~kg} / \mathrm{m}^{3}$ and a viscosity of $1.78 \mathrm{mPa} . \mathrm{s}$ at $20{ }^{\circ} \mathrm{C}$. Although palm oil has higher viscosity than kerosene, its efficiency was comparable.

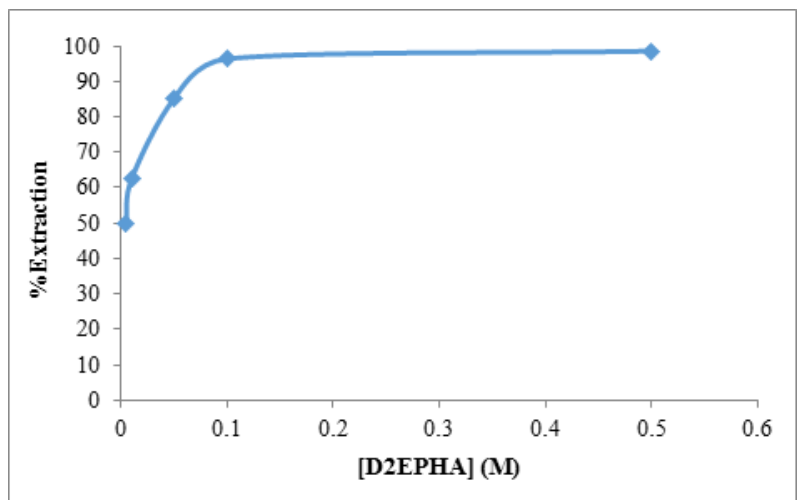

Figure 2 Effect of carrier concentration in liquid-liquid extraction. (Experiment conditions: $[$ dye] $=25 \mathrm{ppm}$, agitation speed $=320 \mathrm{rpm}$,

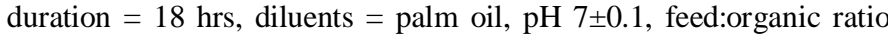
$=1: 1$

For determination the nature of extraction of methylene blue dye, Table 1 shows the distribution ratio (D) of dye. The results show that the distribution ratio of methylene blue dye increased with increases 
the carrier concentration in the organic phase. The Figure 3 in the form of $\log \mathrm{D}$ against $\log$ carrier concentration was plotted. The slope value of 1.006 indicating that dye to carrier concentration ratio was best at 1:1 complex. It can then be assumed that $1 \mathrm{~mol}$ of D2EHPA extract $1 \mathrm{~mol}$ of methylene blue dye to form complex.

Table 1 Distribution ratio of MB in organic solvent

\begin{tabular}{cc}
\hline Carrier concentration $[M]$ & Distribution ratio (D) \\
\hline 0.001 & 0.98 \\
0.005 & 1.00 \\
0.01 & 1.70 \\
0.05 & 6.14 \\
0.1 & 38.06 \\
\hline
\end{tabular}

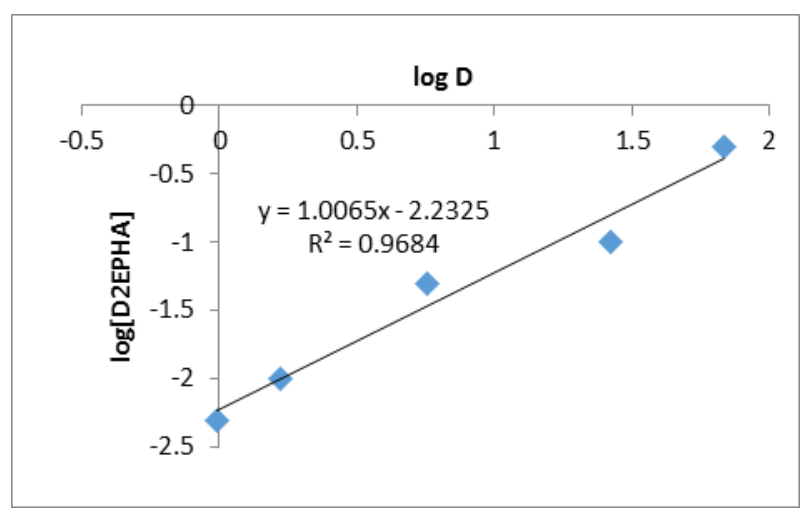

Figure 3 Stoichmetric plot for the equilibrium extraction of methylene blue using D2EHPA as carrier and palm oil as solvent.

$\mathrm{C}_{16} \mathrm{H}_{18} \mathrm{~N}_{3} \mathrm{~S}^{+}$(Dye)+HR( carrier) $\rightarrow \mathrm{C}_{16} \mathrm{H}_{18} \mathrm{~N}_{3} \mathrm{SR}+\mathrm{H}^{+}$

Where HR is the D2EHPA in the palm oil solvent.

\section{Effect of stripping agent type}

For the purpose of recovery methylene blue process, it is desired to extract back the methylene blue from the organic phase. Various types of stripping agents were tested such as Sodium carbonate $\left(\mathrm{Na}_{2} \mathrm{CO}_{3}\right)$, sodium bicarbonate $\left(\mathrm{NaHCO}_{3}\right)$, sodium hydroxide $(\mathrm{NaOH})$ and sodium chloride $(\mathrm{NaCl})$. The extraction performance is shown in Table 2. The highest extraction percentage is $1.0 \mathrm{M} \mathrm{NaHCO} 3$ which is $88 \%$, followed by $73 \%$ for $1.0 \mathrm{M} \mathrm{NaCl}, 3 \%$ for $1.0 \mathrm{M} \mathrm{Na}_{2} \mathrm{CO}_{3}$ and no extraction for $1.0 \mathrm{M} \mathrm{NaOH}$. It indicate that inorganic base are strong acid compared to organic acids, Therefore, stripping performance of the dye become less effectively from organic to aqueous phase [9]. On the other hand, the results also showed an ineffectiveness of strong base in extracting dye from dye loaded organic phase. From the observation an emulsion is formed during the stripping process when using $\mathrm{NaOH}$ due to hydrolysis process of dyes and ion $\mathrm{OH}^{-}$. An emulsion is a mixture of immiscible solvents which refuses to separate into two distinct phases [18]. Therefore, next experiments were carried out using stripping agent of $\mathrm{NaHCO}_{3}$

Table 2 Effect of stripping agents type in stripping process. (Experimental conditions: $[$ dye $]=25 \mathrm{ppm}$, [D2EHPA $]=0.1 \mathrm{M}$, stripping agent concentration $=1.0 \mathrm{M}$, agitation speed $=320 \mathrm{rpm}$, duration $=18 \mathrm{hrs}$, feed:organic ratio 1:1).

\begin{tabular}{cc}
\hline Stripping agent & Stripping percentage (\%) \\
\hline $\mathrm{NaCl}$ & 73 \\
$\mathrm{NaHCO}_{3}$ & 88 \\
$\mathrm{Na}_{2} \mathrm{CO}_{3}$ & 3 \\
$\mathrm{NaOH}$ & 0 \\
\hline
\end{tabular}

\section{Effect of stripping agent concentration}

Figure 4 present the effect of $\mathrm{NaHCO}_{3}$ concentration on the extraction of dye from methylene blue loaded organic phase to stripping phase. Various $\mathrm{NaHCO}_{3}$ concentrations were tested which is $0.1 \mathrm{M}, 0.3 \mathrm{M}, 0.5 \mathrm{M}, 0.6 \mathrm{M}, 0.8 \mathrm{M}$ and $1.0 \mathrm{M}$. It inferred that the increase in stripping agent concentrations, the stripping percentage was increased. This same with previous study [19] indicates that the extraction driving force significantly increases with the different sodium ions concentration in the stripping and organic phase. This is owing to the fact that with the increase in stripping concentration, number of $\mathrm{NaHCO}_{3}$ molecules available for reaction with MBD2EHPA complex also increased. Thus, more dye ions to be stripped out from organic phase. It was found that maximum stripped occurred at $0.6 \mathrm{M} \mathrm{NaHCO} 3$ concentration. Further increase of $\mathrm{NaHCO}_{3}$ concentration to $1.0 \mathrm{M}$ showed no significant effect on the stripping performance. Therefore, $0.6 \mathrm{M}$ was chosen for the next experiment.

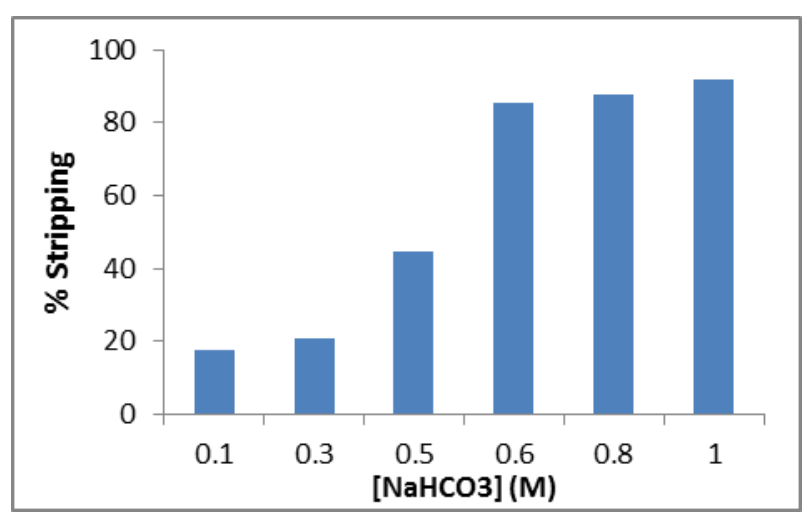

Figure 4 Effect of stripping agent concentrations in stripping process. (Experimental conditions: [dye] $=25 \mathrm{ppm},[\mathrm{D} 2 \mathrm{EHPA}]=0.1 \mathrm{M}$, stripping agent $=\mathrm{NaHCO}_{3}$, agitation speed $=320 \mathrm{rpm}$, duration $=18 \mathrm{hrs}$, feed:organic ratio 1:1).

Figure 5 in the form of $\log \mathrm{D}$ against $\log$ stripping agent concentration was plotted. The slope value of 3.6412 indicating that dye to stripping agent concentration ratio was best at 1:3 complex. It can then be assumed that $3 \mathrm{~mol}$ of $\mathrm{NaHCO}_{3}$ was needed to strip $1 \mathrm{~mol}$ of methylene blue dye from dye loaded organic phase.

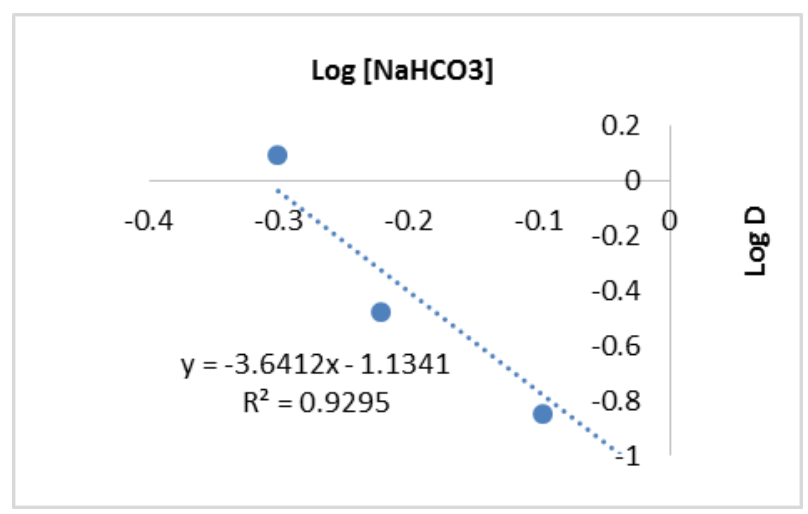

Figure 5 Stoichiometric plots for the equilibrium stripping of methylene blue by using $\mathrm{NaHCO}_{3}$ as stripping agent

The $\mathrm{NaHCO}_{3}$ existed are assumed to be fully reacted with loaded methylene blue-D2EHPA complexes and the nature of the stripped solute can be evaluated as in Equation 5. Therefore, the stripping reaction of methylene blue-D2EHPA with $\mathrm{NaHCO}_{3}$ is:

$$
\mathrm{C}_{16} \mathrm{H}_{18} \mathrm{~N}_{3} \mathrm{SR}+\mathrm{H}^{+} \rightarrow \mathrm{C}_{16} \mathrm{H}_{18} \mathrm{~N}_{3} \mathrm{~S}^{+}+\mathrm{HR}
$$

The $\mathrm{C}_{16} \mathrm{H}_{18} \mathrm{~N}_{3} \mathrm{~S}^{+}$will dissolve in stripping phase and insoluble complexes of D2EHPA (HR) were formed in the organic phase.

\section{Mechanism of basic dye (methylene blue) extraction}

In the extraction process, the D2EHPA as a carrier reacts chemically with cationic methylene blue to form complex of $\mathrm{C}_{16} \mathrm{H}_{18} \mathrm{~N}_{3} \mathrm{SR}$ at the organic-feed interface as represented in Equation 4. Then, stripping process occurred when the $\mathrm{C}_{16} \mathrm{H}_{18} \mathrm{~N}_{3} \mathrm{SR}$ complexes react with $\mathrm{NaHCO}_{3}$ as shown in Equation 5. It is concise the liquidliquid extraction of MB dye with D2EHPA in palm oil as carrier and $\mathrm{NaHCO}_{3}$ as the stripping agent. The slope analysis study of $\log \mathrm{D}$ 
versus $\log [\mathrm{D} 2 \mathrm{EHPA}]$ and $\log \mathrm{D}$ versus $\log \left[\mathrm{NaHCO}_{3}\right]$ as shown in Figure 3 and Figure 5 respectively indicates that one mole of D2EHPA extracts 1 mole of methylene blue dye to form complex and one mole of the complex is needed to reacts with three mole of $\mathrm{NaHCO}_{3}$ to strip the dye into the stripping phase. The extraction and stripping mechanisms are shown in Equations 1 and 2 respectively.

Furthermore, the percentage of extraction and stripping in 5 minutes time are illustrated in Figure 6 and Figure 7. The results show that the extraction rate is high. Almost $80 \%$ of the MB dyes was extracted. It is due to the fact that throughout the extraction process, there are potential of anionic dye to form complexes with the D2EHPA. Meanwhile, the rate of stripping process relies on the strength of $\mathrm{NaHCO}_{3}$ to strip out the dye from the complexes into the strip solution.

\section{Effect of feed solution $\mathrm{pH}$}

The impact of feed $\mathrm{pH}$ is one of the crucial parameter to study on removal of $\mathrm{MB}$ dye because wastewater containing $\mathrm{MB}$ dyes are always discharge at different $\mathrm{pH}$. Figure 8 present the feed phase $\mathrm{pH}$ effect on the MB extraction performance. The difference of $\mathrm{pH}$ between organic phase and the feed phase could affect the extraction efficiency. The range of $\mathrm{pH}$ in this study is from 1 to 5 and 9 tol1 for acidic and basic condition respectively. The $\mathrm{pH}$ of the sample has been adjusted by using $0.1 \mathrm{M} \mathrm{H}_{2} \mathrm{SO}_{4}$ and $0.1 \mathrm{M} \mathrm{NaOH}$. At $\mathrm{pH} 1$, the efficiency of MB dyes extracted was lower at $47 \%$. This is due to present of $\mathrm{H}^{+}$ion in feed solution that competes effectively with the $\mathrm{MB}$ dye cation to react with the carrier. By increased the $\mathrm{pH}$ up to $\mathrm{pH}$ 9 , it shown that the percentage of MB dyes extraction was increased. This is because the MB solution tends to promote the D2EHPA to become negatively charged that enhanced the extraction of positively charged dye cation through electrostatic force of attraction [20]. However, after $\mathrm{pH} \mathrm{9,} \mathrm{the} \mathrm{percentage} \mathrm{of} \mathrm{extraction} \mathrm{is} \mathrm{declined} \mathrm{because}$ at alkaline $\mathrm{pH}, \mathrm{D} 2 \mathrm{EHPA}$ become negatively charged and the dye is negatively charged that contribute to repulsive force of extraction. It justified that increasing the $\mathrm{pH}$ in feed solution might alter the dye molecule from its original structure. In overall, it can be seen that percentage of extraction at $\mathrm{pH} 9$ is higher and can be considered as optimum $\mathrm{pH}$ for $\mathrm{MB}$ dye extraction.

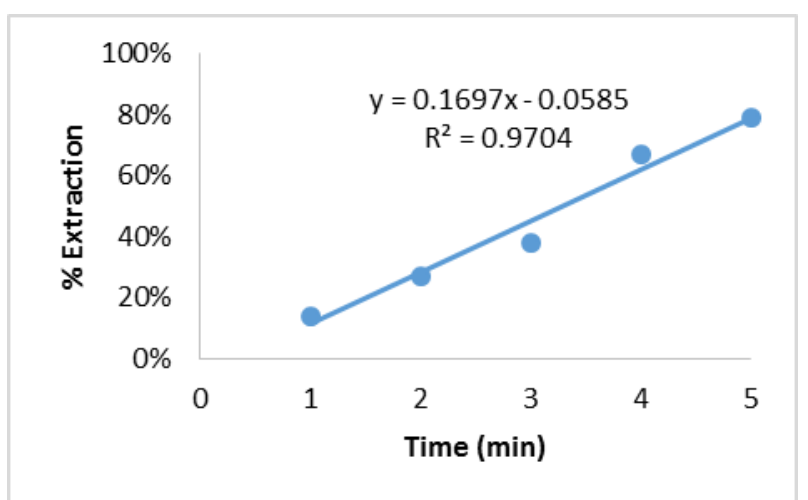

Figure 6 Extraction performance in 5 minutes equilibrium times (Experimental conditions: $[$ dye $]=25 \mathrm{ppm},[\mathrm{D} 2 \mathrm{EHPA}]=0.1 \mathrm{M}$, stripping agent $=\mathrm{NaHCO}_{3}$, agitation speed $=320 \mathrm{rpm}$, duration $=18 \mathrm{hrs}$, feed:organic ratio $1: 1$ ).

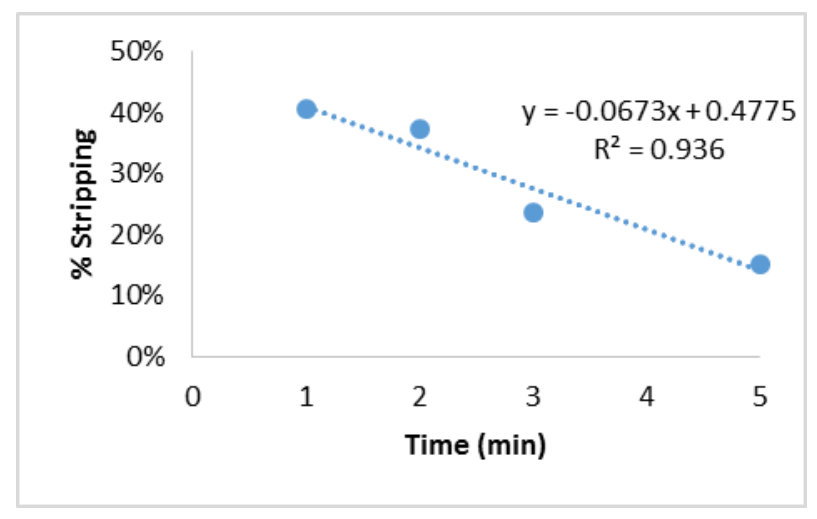

Figure 7 Stripping performance in 5 minutes equilibrium times (Experimental conditions: $[$ dye] $=25 \mathrm{ppm}$, [D2EHPA] $=0.1 \mathrm{M}$, stripping agent $=\mathrm{NaHCO}_{3}$, agitation speed=320rpm, duration $=18 \mathrm{hrs}$, feed:organic ratio 1:1).

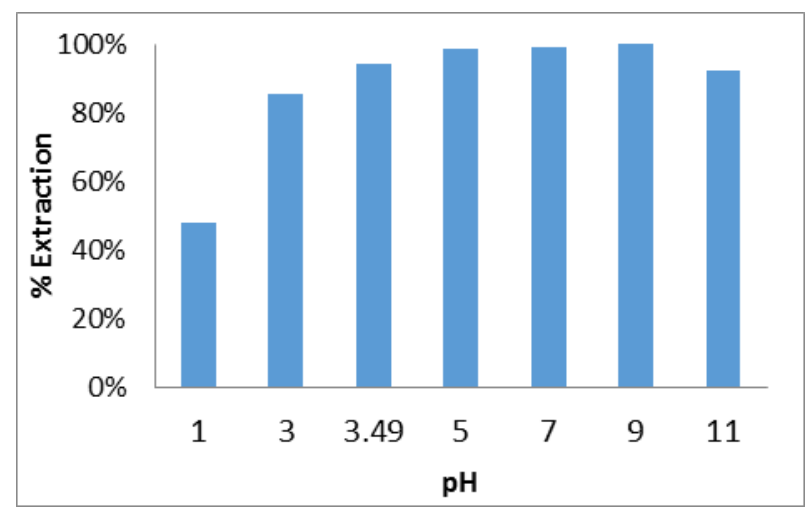

Figure 8: Effect of $\mathrm{pH}$ on extraction performance. (Experimental conditions: $\left[\right.$ dye] $=25 \mathrm{ppm}$, [D2EHPA] $=0.1 \mathrm{M}$, stripping agent $=\mathrm{NaHCO}_{3}$, agitation speed $=320 \mathrm{rpm}$, duration $=18 \mathrm{hrs}$, feed: organic ratio $1: 1, \mathrm{pH} 1$ - 11).

\section{CONCLUSION}

The liquid-liquid extraction method used offers a simple approach for selective extraction of $\mathrm{MB}$ for extraction and recovery. The results showed that LLE is an effective method for removal of MB from aqueous solution. The optimal process conditions are 0.1M D2EHPA in palm oil as a diluent, and $0.6 \mathrm{M}$ of $\mathrm{NaHCO}_{3}$ as a stripping agent. D2EHPA in palm oil is able to extract $100 \%$ of MB from aqueous solution. However, the recovery of dye was yet to be success. Further study on different type of stripping agent will be investigated.

\section{ACKNOWLEDGEMENT}

The authors would like to acknowledge the Ministry of Higher Education (MOHE) and Universiti Teknologi Malaysia (RU Research Grant; GUP:Q.J130000.2546.12H50), Centre of Lipids Engineering and Applied Research (CLEAR), and Universiti Teknologi Malaysia (UTM) for facilities support to make this research possible. 


\section{REFERENCES}

[1] Yang, C., Li, L., Shi, J., Long, C., and Li, A. 2015. Advanced treatment of textile dyeing secondary effluent using magnetic anion exchange resin and its effect on organic fouling in subsequent RO membrane. $J$. of Hazard. Mater. 284: 50-57.

[2] Salleh, M. A. M., Mahmoud, D. K., Karim, W. A. W. A., Idris, A. 2011 Cationic and anionic dye adsorption by agricultural solid wastes: A comprehensive review. Desalination. 280: 1-13.

[3] Jia, Z., Li, Z., Li, S., Li, Y., Zhu, R. 2016. Adsorption performance and mechanism of methylene blue on chemically activated carbon spheres derived from hydrothermally-prepared poly (vinyl alcohol) microspheres. J. of Mol. Liq. 220: 56-62.

[4] Chinoune, K., Bentaleb, K., Bouberka, Z., Nadim, A., Maschke U. 2016. Adsorption of reactive dyes from aqueous solution by dirty bentonite. Appl. Clay Sci. 123: 64-75.

[5] Chen, J., Feng, J., Yan, W. 2016. Influence of metal oxides on the adsorption characteristics of PPy/metal oxides for Methylene Blue. J. of Colloid and Interface Sci. 475: 26-35.

[6] Karaer, H., KayaSynthesis, I. 2016. Characterization of magnetic chitosan/active charcoal composite and using at the adsorption of methylene blue and reactive blue. Microporous Mesoporous Mater. 232: 26-38.

[7] Othman, N., Mili, N., Wong, Y. M. 2011. Liquid-liquid extraction of black b dye from liquid waste solution using Tridodecylamine. J. of Environ. Sci. and Tech. 4(3):324-331.

[8] Othman, N., Mili, N., Idris, A., Zailani, S. N. 2012. Removal of dyes from liquid waste solution: study on liquid membrane component selection and stability. Sustainable Membrane Technology for Energy, Water, and Environment. John Wiley and Sons, USA: $221-229$.

[9] Harruddin, N., Othman, N., Lim, A., Sulaiman, R. N. R. 2015. Selective removal and recovery of Black $B$ reactive dye from simulated textile wastewater using the supported liquid membrane process. Environ. Tech. 36(3): 271-80.

[10] Suvendu, M., Debasis R., Prosenjit S., Deepu G., Sabu T. 2017. Rapid methylene blue adsorption using modified lignocellulosic materials. Process Saf. and Environ. Protection. 107: 346-35.

[11] Ozoh, P. T. E. 1997. Adsorption of cotton fabric dyestuff waste water on Nigeria agricultural semi-activated carbon. Environ. Monit. and Assess. 46: 255-265

[12] Naim, M., El, M., Abd, Y. M. 2002. Removal and recovery of dyestuffs from dyeing wastewaters. Sep. \& Purif. Rev. 31: 171-228.

[13] Ahmad, A. L., Harris, W. A., Ooi, B. S. 2002. Removal of Dye from Wastewater of textile industry using membrane technology. Jurnal Teknologi. 36:31-44.

[14] Muthuraman, G., Teng, T. T., Leh, C. P., Norli, I. 2009. Extraction and recovery of methylene blue from industrial wastewater using benzoic acid as an extractant. J. of Hazard. Mater. 163: 363-369.

[15] Soniya, M., Muthuraman, G. 2015. Comparative study between liquidliquid extraction and bulk liquid membrane for the removal and recovery of methylene blue from wastewater. J. of Ind. and Eng. Chem. 30: 266273.

[16] Venkateswaran, P., K. Palanivelu. 2006. Recovery of phenol from aqueous solution by supported liquid membrane using vegetable oils as liquid membrane. J. of Hazard. Mater. 131(1-3):146-152.

[17] Pezhman, K., Mohammad P., Alireza B., Toraj M. and Omid B. 2013. Pertraction of methylene blue using a mixture of D2EHPA/M2EHPA and sesame oil as a liquid membrane. Chem. Papers. 67(7): 722-729.

[18] Emulsions and Emulsification. 2009. Particle Sciences-Technical Brief. 9: 1-2.

[19] Othman, N., Yi, O. Z., Harruddin, N. 2013. Liquid membrane formulation for removal of Kraft Lignin from simulated liquid waste solution. Malaysian J. of Fundamental and Appl. Sci. 9(1): 41-4.

[20] El, E. S. Z., Fouad, Y. O. 2015. Liquid-liquid extraction of methylene blue dye from aqueous solutions using sodium dodecylbenzenesulfonate as an extractant. Alexandria Engineering Journal. 54(1): 77-81. 